\title{
PENDIDIKAN KESEHATAN TENTANG KESIAPSIAGAAN MENGHADAPI KORBAN BENCANA TERHADAP PENGETAHUAN SISWA DI SMK YADIKA LANGOWAN
}

\author{
Moudy Lombogia, Jon W.Tangka, Maria Terok,Femmy Lumi \\ Jurusan Keperawatan Poltekkes Kemenkes Manado
}

Email Korespondensi: moudylombogia52@gmail.com

\begin{abstract}
The knowledge of students about disaster prevention emergency patients in vocational Yadika Langowan is still lacking where $80 \%$ do not know about Preparedness in facing flood victims. The lack of students' knowledge about preparedness in facing flood victims is due to the lack of exposure of students to health care about preparedness in facing flood victims. The purpose of this study was to determine the effect of health education on preparedness in the face of flood victims on student knowledge. The research design in this study was a onegroup pre-experimental pre-post test design to compare knowledge before and after being given health education about preparedness to face flood victims to students' knowledge. The population in this study were all students of the Manado Cokroaminoto Vocational School and the sample was students of class X and XI 68 people who were determined by purposive sampling. Analysis with the Wilcoxon signed rank test. The results of the test have a significant effect on health education about preparedness to face flood victims to increase knowledge ( $p$-value $=0,000 ; \alpha=0.05)$. The conclusion is that health education about preparedness to face flood victims increases student knowledge
\end{abstract}

Keywords : Disaster, prevention emergency

\section{PENDAHULUAN}

Tingkat resiko bencana selain ditentukan oleh potensi bencana juga di tentukan oleh upaya mitigasi dan kesiapsiagaan dalam menghadapi bencana. Sebagai negara yang berada di daerah rawan bencana, Indonesia harus melakukan tindakan peningkatan upaya dalam kesiapsiagaan untuk meminimalkan dampak bencana (Herdwiyanti dan Sudaryono, 2013).

Negara Indonesia adalah negara yang sangat rawan bencana baik bencana alam, non alam maupun bencana sosial. Kejadian bencana tersebut kerap kali menimbulkan krisis kesehatan akibat jatuhnya korban meninggal, luka berat, luka ringan, pengungsian dan rusaknya fasilitas kesehatan. Selama kurun waktu 5 tahun antara tahun 2010-2014 jumlah kejadian bencana di Indonesia mencapai 1.907 kejadian bencana, terdiri dari 1.124 bencana alam, 626 bencana non alam dan 157 bencana sosial. Sedangkan untuk tahun 2014 jumlah kejadian bencana sebanyak 456 kejadian, terdiri dari 227 bencana alam (49\%), 197 bencana non alam (44\%), dan 32 bencana sosial $(7 \%)$. Kejadian bencana tersebut menimbulkan jumlah korban sebanyak 1.699.247 orang, terdiri dari 957 orang korban meninggal, 1.932 orang luka berat/dirawat inap, 694.305 orang luka ringan/rawat jalan, 391 orang hilang dan 1.001.662 pengungsi (Pusat Krisis
Kesehatan, Kemenkes, 2015).

Banjir di Kota Manado yang terjadi pada tanggal 15 Januari 2014, Berdasarkan data curah hujan UPT BMKG dan pos kerjasama di wilayah kota Manado yang terkena dampak banjir terlihat bahwa curah hujan dengan intensitas yang cukup tinggi terjadi pada tanggal 14/15 Januari 2014. Stasiun Meteorologi Sam Ratulangi Manado mencatat nilai curah hujan ekstrim $145 \mathrm{~mm}$ (kriteria curah hujan ekstrim $>100 \mathrm{~mm} /$ hari). Intensitas curah hujan yang terekapitulasi oleh BMKG Sulawesi Utara menunjukkan di beberapa tempat mengalami curah hujan ekstrim (> $100 \mathrm{~mm} /$ hari) dengan sebaran yang variatif. Hal ini yang membuat hujan terjadi hampir sepanjang hari dengan intensitas sedang hingga sangat lebat yang berefek pada terjadinya banjir di Sulawesi Utara (Dayantolis \& Fitri, 2014)

Menurut Undang-Undang Nomor 24 Tahun 2007 pasal 35 huruf $\mathrm{g}$ penyelengggaraan penanggulangan bencana dalam situasi tidak terjadi bencana yaitu dengan pendidikan dan pelatihan.

Salah satu bentuk pendidikan kepada pelajar adalah lewat penyuluhan kesehatan dimana pendidikan yang dapat diberikan mengenai kesiapsiaaan dalam menghadapi korban bencana banjir. Pelajar merupakan agen informasi bagi keluarga, mereka paling cepat dan tidak hanya mampu memadukan pengetahuan baru bagi kehidupan seharihari tetapi menjadi sumber pengetahuan 
bagi orang di sekelilingnya (Khoirunisa, Rasyidin, \& Onesia, 2014).

Data-data di atas menunjukkan banyak jumlah korban yang meninggal dan mengalami kecacatan saat setelah terjadi bencana begitu pula begitu banyak kerugian yang terjadi. Padahal kalau masyarakat sudah terlatih dan tahu tentang cara menolong dan mengevakuasi korban pada saat bencana pasti angka kematian, lukaluka dan kecacatan akan berkurang dan bisa jadi tidak ada korban jiwa dan cacat permanen pada saat terjadi bencana.

\section{METODE}

\section{Desain, tempat dan waktu penelitian}

Desain penelitian yang di gunakan dalam penelitian ini adalah penelitian secara pre experimental design dengan menggunakan desain one-group pre testpost test design yaitu rancangan penelitian ini dilakukan dengan cara sebelum diberikan treatment/ perlakuan variable diobservasi/ diukur terlebih dahulu (pretest) setelah itu dilakukan treatment/perlakuan dan setelah treatment dilakukan pengukuran/observasi (posttest) (Hidayat,2017). Penelitian ini untuk melihat pengaruh pendidikan kesehatan tenang kesiapsiagaan bencana terhadap pengetahuan siswa.

Lokasi Penelitian di Sekolah Menengah Kejuruan Yadika Langowan, waktu penelitian Oktober 2018.

\section{Jumlah dan cara pengambilan subjek}

Populasi adalah keseluruhan objek penelitian atau objek yang diteliti (Notoatmodjo, 2012). Populasi penelitian adalah seluruh siswa-siswi SMK Yadika Langowan yang berjumlah 112 orang. Sampel diambil dengan Rumus Slovin dengan menggunakan metode Purposive sampling yaitu berjumlah 68 Siswa.

\section{Pengolahan data dan analisis data}

Teknik pengumpulan data dalam penelitian ini adalah dengan cara wawancara terpimpin dan observasi terstruktur. Sumber data yaitu : Data primer pada penelitian ini didapatkan melalui data primer yaitu data yang secara langsung dari subjek penelitian yaitu didapatkan dari pertama pengisian kuesioner tentang pengetahuan mengenai kesiapsiagaan menghadapi korban bencana banjir yang nantinya diisi oleh Siswa di SMK Yadika Langowan, sebelum dan sesudah pendidikan kesehatan. Data sekunder adalah data yang didapatkan dalam penelitian melalui data pendukung dari institusi SMK Yadika Langowan. mengenai data-data siswa.

Data yang didapatkan berdistribusi normal, sehingga peneliti melakukan uji hipotesis dengan menggunakan uji Wilcoxon Signed Rank Test dengan derajat kesalahan $0.05 \%$ atau derajat kemaknaan $95 \%$.

\section{HASIL}

Hasil penelitian dilakukan pada bulan Oktober 2018 dibagi menjadi dua, yakni hasil penelitian univariat dan bivariat

\section{Karakteristik responden}

Karakteristik responden menunjukkan bahwa jumlah siswa berdasarkan usia terbanyak adalah yang berusia 15 tahun sebanyak 32 orang $(47,05 \%)$. Jumlah siswa berdasarkan jenis kelamin terbanyak adalah laki-laki dengan jumlah 45 orang $(66,17 \%)$.

\section{Hasil analisis univariat \\ Pengetahuan}

responden

menunjukkan bahwa, kesiapsiagaan menghadapi korban bencana sebelum diberikan pendidikan kesehatan tentang kesiapsiagaan menghadapi korban bencana banyak pada kategori kurang $76.47 \%$, dan pengetahuan kesiapsiagaan menghadapi korban bencana setelah diberikan pendidikan Kesehatan sebagian besar pada kategori baik $64.70 \%$.

\section{Hasil Analisis Bivariat}

Perbedaan rata - rata pengetahuan sebelum dan setelah diberikan pendidikan kesehatan tentang kesiapsiagaan menghadapi korban bencana.

Perbedaan rata - rata pengetahuan sebelum dan setelah diberikan pendidikan kesehatan, tentang kesiapsiagaan menghadapi korban bencana yang dianalisis dengan Wilcoxon Signed Rank Test. Hasil analisis menunjukkan bahwa nilai tengah pengetahuan sebelum pendidikan kesehatan yaitu 10.00 dengan minimum-maximum 3-16 dan nilai rata-rata 10.00 dengan SD 2.748, dan nilai tengah pengetahuan setelah pendidikan kesehatan yaitu 16.50 dengan minimum-maximum 1018 dan nilai rata-rata 15.49 dengan SD 2.340 Hasil uji statistic Wilcoxon Rank Signed Test, terdapat pengaruh pendidikan kesehatan terhadap pengetahuan siswa $(p=0.000 ; \alpha=0.05)$ 


\section{PEMBAHASAN}

Hasil uji Wilcoxon Signed Ranks Test dengan menggunakan statistik $\mathrm{z}$ didapatkan nilai z -6.716 dengan tingkat kesalahan 0,05 dengan tingkat kepercayaan 95\% maka nilai $p$-value (Asymp. Sig 2 tailed) sebesar 0,000 yang berarti $\mathrm{H}_{a}$ diterima. Hasil ini menunjukkan bahwa secara statistik ada pengaruh yang signifikan dalam pendidikan kesehatan tentang kesiapsiagaan menghadapi korban bencana terhadap pengetahuan siswa di SMK Yadika Langowan.

Penelitian ini sejalan dengan penelitian Matura (2011) tentang pengaruh pendidikan kesehatan terhadap perubahan tingkat pengetahuan masarakat di desa Bayuwangi yang menyatakan ada pengaruh penyuluhan kesehatan terhadap perubahan tingkat pengetahuan masyarakat dengan nilai signifikansi $p<0,05(p=0,03)$.

Hasil penelitian ini juga didukung penelitian sebelumnya oleh Dien, Kumaat, \& Malara (2015) dengan judul pengaruh penyuluhan kesehatan terhadap kesiapsiagaan menghadapi bencana gempa bumi pada siswa SMP Kristen Kakaskasen Kota Tomohon dimana terdapat pengaruh yang signifikan antara sebelum dan sesudah diberikan penyuluhan kesehatan tentang kesiapsiagaan gempa bumi.

Penelitian ini juga sejalan dengan penelitian Sunaryo (2004) yang mengatakan bahwa pengetahuan merupakan objek yang sangat penting untuk terbentuknya perilaku terbuka (overt behavior). Perilaku yang didasari pengetahuan umumnya bersifat langgeng dimana seorang yang memiliki pengetahuan yang baik paling tidak telah mengetahui suatu masalah dan dapat menganalisa sehingga melakukan tindakan yang lebih baik dari seseorang yang tidak tahu apa-apa.

Menurut Sutopo (2016) menyatakan bahwa terdapat 3 pilar penyelenggaraan penanggulanan bencana adalah :

1. Pemerintah/pemerintah daerah,

2. masyarakat sipil,

3. lembaga usaha/sektor swasta,

Kaitannya dengan penelitian ini dimana siswa SMK Yadika Langowan yang merupakan komponen masyarakat diberikan pendidikan kesehatan pada kesiapsiagaannya dalam penanggulangan korban bencana berupa evakuasi korban bencana, bantuan hidup dasar bagi awam, balut bidai pada simulasi bencana, supaya dengan pengetahuan yang dimiliki dapat berpartisipasi aktif jika terjadi bencana. Menurut
Sutopo
pada penanggulangan bencana memerlukan kapasitas yang terdiri dari

1. Kapasitas kelembagaan (ada tidaknya BPBD),

2. Kapasitas sumber daya yaitu sumber daya manusia (pelatihan, relawan, masyarakat), prasarana seperti alat transportasi, komunikasi, kantor,

3. Kapasitas IPTEK

4. Kapasitas manajemen (prosedur koordinasi, komando, dan pelaksanaan penanggulangan bencana),

Sejalan dengan penelitian ini siswa yang telah dilatih penanggulangan bencana mereka dapat secara aktif menjadi relawan pada saat terjadi bencana dilokasi mereka tinggal, maupun daerah lain jika membutuhkan tenaga seperti mereka.

Menurut Supartini et al. (2017) menyusun rencana latihan kesiapsiagaan, yang melibatkan populasi lingkungan tempat tinggal, kantor, sekolah, area public, salah satu latihan tersebut berisi membuat scenario latihan kesiapsiagaan. Skenario dibuat berdasarkan kejadian yang paling mungkin terjadi didesa.

Penelitian ini menunjukkan bahwa sebelum diberikan perlakuan ditemukan pengetahuan sebagian besar dengan pengetahuan kurang dan setelah diberikan pendidikan kesehatan, terjadi perubahan pengetahuan yang sebagian besar baik. Siswa yang sangat antusias mempelajari materi kesiapsiagaan bencana, baik materi teori maupun praktek. Pengetahuan tentang kesiapsiagaan adalah serangkaian kegiatan yang harus diketahui oleh siswa untuk mengantisipasi situasi bencana dalam bentuk simulasi bencana gempa bumi, mengingat lokasi sekolah SMK Yadika Langowan berdekatan dengan gunung Soputan yang aktif dan sewaktu-waktu menimbulkan gempa yang jika terjadi gempa secara cepat dan tepat guna dapat dalam melakukan pertolongan. Kesiapsiagaan menghadapi bencana adalah suatu kondisi suatu masyarakat yang baik secara individu maupun kelompok yang memiliki kemampuan secara fisik dan psikis dalam menghadapi bencana,

Sehingga menurut peneliti bahwa pelajar sebagai seorang awam dapat melakukan kesiapsiagaan menghadapi korban bencana pada siapapun dalam keadaan gawat darurat terutama pada orang 
yang mengalami henti jantung dan henti nafas. Peranan orang awam sebagai penemu pertama korban sangat berpengaruh. Meskipun keterlambatan hanya beberapa menit jantung seseorang berhenti, dapat memberi perbedaan antara hidup dan mati, dan memberi bantuan sementara sampai perawatan medis yang kompeten.

\section{KESIMPULAN}

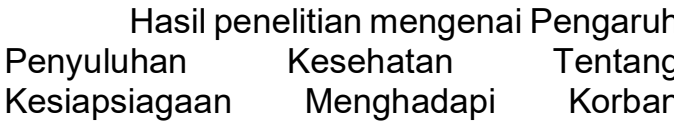
Bencana Banjir terhadap Pengetahuan Siswa di SMK Yadika Langowan.pada bulan Oktober 2018, dapat disimpulkan bahwa Pengetahuan siswa sebelum Penyuluhan Kesehatan Tentang Kesiapsiagaan Menghadapi Korban Bencana Banjir pada kategori kurang, dan setelah Penyuluhan Kesehatan Tentang Kesiapsiagaan Menghadapi Korban Bencana Banjir pada kategori baik. Terdapat Pengaruh Penyuluhan Kesehatan Tentang Kesiapsiagaan Menghadapi Korban Bencana Banjir terhadap pengetahuan siswa SMK Yadika Langowan.

\section{SARAN}

Berdasarkan kesimpulan diatas maka penulis memberikan saran sebagai berikut

\section{SMK Yadika Langowan.}

Memperluas pengetahuan siswa tentang Kesiapsiagaan Menghadapi Korban Bencana Banjir, sebaiknya pihak SMK Yadika Langowan menjadikan Kesiapsiagaan Menghadapi Korban Bencana Banjir sebagai kegiatan ekstrakulikuler sekolah.

\section{Institusi Pendidikan}

Jurusan Keperawatan Politeknik Kesehatan Manado melakukan pengabdian masyarakat yakni memberikan Pendidikan Kesehatan Tentang Kesiapsiagaan Menghadapi Korban Bencana Banjir untuk seluruh SMK dan Masyarakat di Sulawesi utara yang belum terpapar dengan Penanganan Kesiapsiagaan Menghadapi Korban Bencana Banjir supaya siswa dan masyarakat khususnya orang awam memiliki pengetahuan yang baik

\section{UCAPAN TERIMA KASIH}

Pihak SMK Yadika Langowan baik kepala sekolah, siswa, guru-guru yang berpartisipasi aktif pada penelitian ini mulai dari menyiapkan siswa yang akan dilatih, ruangan dan fasilitas yang mendukung sehingga terjadi simulasi bencana. Mahasiswa Poltekkes Kemenkes Manado yang tergabung dalam Tim Siaga Bencana, yang turut mengarahkan siswa-siswa peserta pelatihan baik dalam praktek maupun pada saat simulasi bencana yang dengan kemampuan ilmu dan kompetensi yang dimiliki mampu melakukan dengan optimal.

\section{DAFTAR PUSTAKA}

Dien, Kumaat, Malara (2015), Pegaruh Penyuluhan Kesehatan terhadap Kesiapsiagaan Menghadapi Bencana Gempa Bumi pada siswa SMP Kristen Kakaskasen Kota Tomohon, Jurnal Keperawatan Unsrat, 2015, https://www.neliti.com

Dayantolis \& Fitri (2014). Tinjauan Klimatologis Banjir Manado, UPT Stasiun Klimatologi Manado, BMKG Sulut. Bencanasulut.wordpress.com

Herdwiyanti, F. \& Sudaryono. (2013). Perbedaan Kesiapsiagaan Menghadapi Bencana Di Tinjau Dari Tingkat Self-Eficacy Pada Anak Usia Sekolah Dasar Di Daerah Dampak Bencana Gunung Kelud. Jurnal Fakultas Psikologi Universitas Airlangga. (Diakses Pada Tanggal 5 Agustus 2018)

Hidayat,A.A.A, (2017), Metodologi Penelitian Keperawatan dan Kesehatan, Salemba Medika, Jakarta.

Khoirunisa, N., Rasydin, N.I., \& Onesia, I. (2014). Tingkat Kesiapsiagaan dan Implementasi Mitigasi Bencana Bagi Pelajar Di Lereng Gunung Berapi. Jurnal Universitas Muhamadiyah Surakarta. Diakses Pada Tanggal 5 Agustus 2018

Matura (2011). Pedoman Nasional Manajemen Bencana di Indonesia. Gama Media. Yogyakarta.

Notoatmodjo, S. (2012). Metodologi Penelitian Kesehatan. Jakarta. Rineka Cipta. Jakarta 
Pusat Krisis Bencana Kementrian Kesehatan RI, (2015), Publikasi Lewat Web, Diakses Tanggal 24 Maret 2018 pukul 18.30 .

Sunaryo, (2004). Disaster Manajemen di Negeri Rawan Bencana. Cetakan Pertama, PT Aksara Grafika Pratama, Jakarta.

Sutopo, (2016), Manajemen Bencana di Indonesia, Badan Nasional Penanggulangan Bencana. Sibima. pu.go.id (diakses 29 Januari 2019)
Supartini, (2017), Buku Latihan Kesiapsiagaan Bencana Membangun Kesadaran Kewaspadaan dan Kesiapsiagaan dalam menghadapi Bencana, BNPB, Jakarta

Undang-undang Republik Indonesia Nomor 24 Tahun 2007 Tentang Penanggulangan Bencana (http:// www.bnpb.go.id/uploads/migration/p ubs.pdf (di akses pada tanggal 20 Oktober 2018 pukul 18.30 Wita) 


\section{LAMPIRAN}

Tabel 1 Distribusi Responden Berdasarkan Kelompok Umur Siswa Di SMK Yadika Langowan pada Oktober 2018

\begin{tabular}{cccc}
\hline No & Kelompok Umur & Jumlah & $\%$ \\
\hline 1 & 14 & 9 & 13,23 \\
2 & 15 & 32 & 47,05 \\
3 & 16 & 27 & 39,70 \\
\hline Total & & 68 & 100 \\
\hline
\end{tabular}

Tabel 2 Distribusi Responden Berdasarkan Jenis Kelamin Siswa Di SMK Yadika Langowan.Pada Bulan Oktober 2018

\begin{tabular}{cccc}
\hline No & Jenis Kelamin & Jumlah & $\%$ \\
\hline 1 & Laki-Laki & 45 & 66,17 \\
2 & Perempuan & 23 & 33,82 \\
\hline Total & & 68 & 100 \\
\hline
\end{tabular}

Tabel 3 Pengetahuan Siswa sebelum diberikan Pendidikan Kesehatan Tentang Kesiapsiagaan Menghadapi Korban Bencana Banjir Di SMK Yadika Langowan pada Oktober 2018

\begin{tabular}{lccccccc}
\hline \multirow{2}{*}{ Variabel } & \multicolumn{5}{c}{ Ketegori } \\
\cline { 2 - 8 } & & \multicolumn{1}{c}{ Baik } & \multicolumn{2}{c}{ Cukup } & \multicolumn{2}{c}{ Kurang } \\
\cline { 2 - 8 } & $\mathbf{n}$ & $\%$ & $\mathbf{n}$ & $\%$ & $\mathbf{n}$ & $\%$ \\
\hline $\begin{array}{l}\text { Pengetahuan Siswa } \\
\text { Pretest }\end{array}$ & 2 & 2.94 & 14 & 20.58 & 52 & 76.47 \\
\hline
\end{tabular}

Tabel 4 Pengetahuan setelah diberikan Pendidikan Kesehatan Tentang Kesiapsiagaan Menghadapi Korban Bencana Banjir Di SMK Yadika Langowan pada Oktober 2018

\begin{tabular}{lcccccc}
\hline \multirow{2}{*}{ Variabel } & \multicolumn{6}{c}{ Ketegori } \\
\cline { 2 - 7 } & \multicolumn{2}{c}{ Baik } & \multicolumn{2}{c}{ Cukup } & \multicolumn{2}{c}{ Kurang } \\
\cline { 2 - 7 } & $\mathbf{n}$ & $\%$ & $\mathbf{n}$ & $\%$ & $\mathbf{n}$ & $\%$ \\
\hline $\begin{array}{l}\text { Pengetahuan Siswa } \\
\text { Posttest }\end{array}$ & 44 & 64.70 & 12 & 17.64 & 12 & 17.64 \\
\hline
\end{tabular}

Tabel 5 Hasil analisis pengetahuan siswa sebelum dan setelah diberikan pendidikann kesehatan tentang kesiapsiagaan menghadapi korban bencana Banjir di SMK Yadika Langowan pada Oktober 2018.

\begin{tabular}{lccc}
\hline \multicolumn{1}{c}{ Variabel } & $\begin{array}{c}\text { Median } \\
\text { (Minimum-Maximum) }\end{array}$ & Mean (SD) & $p$ \\
\hline Pengetahuan ibu & & & \\
PreTest & $10.00(3-16)$ & 10.00 & 0.000 \\
PostTest & $16.50(10-18)$ & 15.49 & \\
\hline
\end{tabular}

